\title{
What physiological changes and cerebral traces tell us about adhesion to fiction during theater-watching?
}

\author{
Marie-Noëlle Metz-Lutz ${ }^{1}$, Yannick Bressan ${ }^{2}$, Nathalie Heider ${ }^{1}$ and Hélène Otzenberger ${ }^{1}$ \\ Laboratoire d'Imagerie et Neurosciences Cognitives, FRE 3289 Centre National de la Recherche Scientifique, Faculté de Médecine, Université de Strasbourg, \\ Strasbourg, France \\ 2 Équipe de Recherches Théâtrales et Cinématographiques, Université Paris Ouest Nanterre La Défense, Paris, France
}

\section{Edited by:}

Ivan Toni, Radboud University,

Netherlands

Reviewed by:

Ricarda I. Schubotz, Max Planck Institute for Neurological Research,

Germany

Leonhard Schilbach, University of

Cologne, Germany

${ }^{*}$ Correspondence:

Marie-Noëlle Metz-Lutz, Laboratoire

$d^{\prime}$ Imagerie et Neurosciences

Cognitives, FRE 3289 Centre National

de la Recherche Scientifique, Faculté

de Médecine, Université de

Strasbourg, 4, rue Kirchleger, F-67085

Strasbourg Cedex, France.

e-mail: metzlutz@linc.u-strasbg.fr
Live theater is typically designed to alter the state of mind of the audience. Indeed, the perceptual inputs issuing from a live theatrical performance are intended to represent something else, and the actions, emphasized by the writing and staging, are the key prompting the adhesion of viewers to fiction, i.e., their belief that it is real. This phenomenon raises the issue of the cognitive processes governing access to a fictional reality during live theater and of their cerebral underpinnings. To get insight into the physiological substrates of adhesion we recreated the peculiar context of watching live drama in a functional magnetic resonance imaging (fMRI) experiment, with simultaneous recording of heart activity. The instants of adhesion were defined as the co-occurrence of theatrical events determined a prioriby the stage director and the spectators' offline reports of moments when fiction acted as reality. These data served to specify, for each spectator, individual fMRI time-series, used in a random-effect group analysis to define the pattern of brain response to theatrical events. The changes in this pattern related to subjects' adhesion to fiction, were investigated using a region of interest analysis. The results showed that adhesion to theatrical events correlated with increased activity in the left BA47 and posterior superior temporal sulcus, together with a decrease in dynamic heart rate variability, leading us to discuss the hypothesis of subtle changes in the subjects' state of awareness, enabling them to mentally dissociate physical and mental (drama-viewing) experiences, to account for the phenomenon of adhesion to dramatic fiction.

Keywords: human communication, theater, fMRI, dynamic HRV, fiction, narrative processing, state of consciousness

\section{INTRODUCTION}

According to Aristotle, theater results from a human disposition for storytelling and imitation, "one instinct of our (human) nature" (Aristotle, 350 B.C.E). Acting out stories in front of an audience has remained popular, whatever the cultural context, despite the tremendous technological developments intervened since the invention of motion picture, or video. These media display a facsimile of the real world on a fixed physically constrained space, i.e., the screen. The performance displayed is actually over by the time it is available to be viewed, and it may be watched anywhere, anytime. It is definitively "only a frame and a series of individual images" (Godard, 1999) of which the illusion of motion, and consequently of life, results from the effect of persistence of vision in the viewer.

By contrast, in live theater, the perceptual inputs, are not pictures but real-time "imitations", designed to represent on the spot something else: a real, live actor, is a character as well, four boards and a chair on stage become in the viewers' mind the court of Elsinore. Hence, theater may be said to exhibit simultaneously two realities, one "actual", related to the performance itself, the other "fictional", suggested by the performance. In live theater, actors perform in the flesh, so that at any moment the audience faces both the performers and the characters they pretend to be. Besides, at any time, the performance may evolve as a function of the actors' relationship with the audience, and the spectators may flip from the actual reality to the fiction depending on their own engrossment and/or the suggestiveness of the play. Therefore transition from the reality actually grasped from sensory information to the represented reality is made possible owing to the potency of the phrasing and acting, promoted by the stage director's artistic concept and envisioning of the drama. In his Poetics, Aristotle emphasized the key function of both writing and staging, and the distinction between theater and narrative; "tragedy, is an imitation of an action that is serious, complete, and of a certain magnitude; in language embellished with each kind of artistic ornament, the several kinds being found in separate parts of the play; in the form of action, not of narrative" (Aristotle, 350 B.C.E). Another essential component, which may assist in the shift from actual reality to fiction in live theater deals with the suspension of disbelief based on the agreement by the spectators to provisionally suspend their judgment. According to Coleridge (1817) who coined the notion to support non-realistic elements in literature, the "willing suspension of disbelief" necessitates "to transfer from our inward nature a human interest and a semblance of truth" to enjoy a fantastic story.

The ability for a spectator of live theater to enter a fictional reality would therefore imply, first a readiness to sacrifice realism, even logic and believability, and second a capacity to "contextualize" immediate sensory information processing. The first condition is a matter of culture. Like more recent forms of live arts, i.e., happenings or visual performing arts, theater is a time-based form of 
art. It originates from the simultaneous exhibition of two facets of objects, movements, persons, and words. The actor/character duality exemplifies the "dual reality" inherent in live theater. As Artaud (1938) put it, reality is a matter of consensus, the one a theatergoer accepts when watching a play and, for a time, pretends that what he is seeing is real. As to the second condition, it would rely on particular mental processes enabling spectators to go beyond what perceptual inputs tell them about the actual reality, and thus "adhere" to the fictional reality. The paradox of being moved by what we know to be representations of events that are not really happening, central in esthetics, has been disputed by philosophers (Schaper, 1978; Rosebury, 1979). They argued about the "suspension of disbelief" hypothesis, distinguishing two kinds of beliefs; the beliefs entailed by the knowledge that the play is an intentionally made human artifact, and the beliefs relevant to what is going on in the fiction. In other words, when we attend a play we know that the question of the existence of the characters and events does not arise, and beliefs based on this knowledge have to be suspended so that they do not contradict our beliefs in the fiction. The combination of these two conditions raises the issue of the cognitive processes governing access to a fictional reality in live theater, and of their cerebral underpinning.

At first glance, the principal cognitive process involved when attending a dramatic play could come close to that at work during reading or listening comprehension of a narrative. However, while narrative comprehension requires from readers or listeners coherent representations of the characters, places, and events recounted in the text, the understanding of a performance assumes that one agrees that the actual facts, i.e., actors, scenery, and events are intended to depict a fiction. Accordingly, adhesion to the represented reality, i.e., fiction, would rather involve a change of perspective in sensory input processing. Indeed, in opposition to story readers or listeners, drama viewers instead of being urged to generate representations of the different narrative components, are invited to perceive the intended meaning of the performance and accordingly to cross the "fourth wall", the invisible wall at the front of the stage, to enter in or adhere to the world of the play, that is the fiction.

One cognitive process potentially involved in this phenomenon would resemble the processing of metaphor, a rhetorical device through which the sense of a word is transferred into a new sense. As it happens, actions performed by actors on stage, as well as pieces of the scenery, are intended to represent a reality other than that which originates from the actual sensitive inputs. In this regard, the style of writing and the artistic vision governing the staging of a play are of paramount importance.

Another psychological construct possibly at work when viewing a dramatic play could relate to empathy, through which viewers adopt someone else's perspective (Batson et al., 1997). Indeed spectators are prone to understand and even sympathize with the physical or affective experience of the characters, distinct from the actors whom they are actually facing. Such a shift in perspective could also be one of the cognitive processes allowing spectators to bypass physical reality and adhere to fiction.

The few studies having examined how the brain distinguishes reality from fiction were based on monitoring tasks in which the subjects had either to discriminate fiction generated from internal cognitive functions such as thought or imagination, from information derived from the outside world by perceptual processing (Simons et al., 2008), either to evaluate reality-based scenarios involving real or fictional characters (Abraham et al., 2008) or to distinguish perceived and imagined events (Turner et al., 2008). Besides purely fiction-related aspects, studying adhesion to the fiction represented by a theatrical play must take into account the fact that it is in essence a subjective phenomenon, which occurs at variable moments depending on the disposition of each spectator in conjunction with the impact of theatrical events. Owing to the importance of subjectivity inherent in this peculiar phenomenon unique to theater, in order to study it, it is mandatory to identify and isolate the instants when the spectators enter the fictional world that lies beyond what their senses perceive. One way to identify these fugitive instants of adhesion to fiction may be to discern the moments when the spectators' mind meets with the intentions of the playwright or stage director. This implies to analyze the personal feelings of each spectator throughout the dramatic performance and see how they tally with the theatrical events related to the intentions of the author, which may be spotted in the text, and reinforced by particular direction markers. Whereas such theatrical events may easily be determined from the stage director prior to the performance, the spectators' feelings are totally inherent in their personal experience. New methodological approaches have recently been proposed to investigate phenomenal consciousness from a first-person perspective (Varela, 1996; Varela and Shear, 1999). For example, the verbal reports of subjects describing subtle changes in mental states during their involvement in an experiment may be integrated with the quantitative analysis of neural activity and serve to detect and interpret neural processes (Lutz et al., 2002; Northoff and Heinzel, 2006). Such a method, based on the subjects' verbal reports of their interpretations and feelings throughout the whole experiment seemed appropriate to seize changes in mental states induced by the ongoing performance, and particularly to determine for each spectator the instants when (s)he adhered to the fiction, with a view to analyze the corresponding neural correlates. Besides the phenomenological approach of mental states throughout a given experiment, another challenging issue was the determination of neural substrates within a realistic context. Innovative approaches to analyzing functional magnetic resonance imaging (fMRI) data collected during dynamic naturalistic tasks have been adopted in recent studies for different purposes: to identify brain regions involved in the perception of personally meaningful event-boundaries during the free viewing of movie clips of ordinary daily events (Zacks et al., 2001), to probe functional brain specialization for visual attributes in natural complex situations such as movie viewing (Bartels and Zeki, 2004), to investigate the neural correlates of spontaneous thoughts during ongoing real-world tasks (Spiers and Maguire, 2006) or of reciprocity in social interaction on the basis of online measurement of subjects' gaze behavior (Wilms et al., 2010).

Investigating the neural correlates of adhesion, i.e., of the viewers' shift from actual reality to that assumed to be conveyed through the dramatic performance in the flesh of an actor, required first the setting up of an original fMRI experiment, and second the use of a specific methodology for data analysis. 
The fMRI experiment aimed at recreating, within the laboratory, a valid ecological design of this complex social interaction, based on the unique relationship between actor and spectator, which typically occurs through the invisible "fourth wall" of the stage.

To pick out, within the brain activity elicited by watching the actor's performance, transient signal changes relevant to the adhesion of each spectator, we used an analytical method associating first-person data collected a posteriori, with specifications about the theatrical events defined a priori by the stage director. With the aim of tracking down possible physiological correlates, such as instant changes in dynamic heart rate variability (HRV) time-locked to the shift in the spectators' mind from reality to fiction, an electrocardiogram (ECG) was recorded throughout the experiment.

We anticipated that as a form of storytelling, live theater would activate in the drama viewer's brain regions typically engaged in the comprehension of narratives, e.g., the medial prefrontal cortex (mPFC), the precuneus-posterior cingulate cortices (PCC), the anterior temporal lobes, and areas along the middle and superior temporal gyri and the inferior frontal cortex, with the involvement of the right hemisphere (Xu et al., 2005; Ferstl et al., 2008; Yarkoni et al., 2008). With respect to activation specifically associated with adhesion, we hypothesized that it would recruit brain areas such as the left lateral inferior frontal gyrus (IFG; Rapp et al., 2004) involved in metaphor processing (i.e., whereby the sense of words or actions would be shifted into a new sense, related to the fiction), and/or regions in the posterior temporal parietal region (Gallagher et al., 2000; Saxe and Kanwisher, 2003; Vollm et al., 2006) involved in thinking about others thinking, or in adopting someone else's perspective (allowing the spectator to regard a fiction as reality).

Processing the actions and scenery as metaphors could be one cognitive process related to the knowledge that a play is an intentionally made human artifact, allowing to deal with a fiction as reality and as a consequence to consider a character as "the other", by whom one may be moved. In order to complement the phenomenological account of adhesion, we expected to find in the ECG data physiological correlates of "esthetic emotion" in the form of increased dynamic HRV.

\section{MATERIALS AND METHODS PARTICIPANTS}

Nineteen volunteers (mean age 21, range 19-32, 10 females) joined the study. They were students of Humanities or Arts. Thirteen studied drama, the others were theatergoers. They were right-handed according to the Edinburgh handedness inventory (Oldfield, 1971). They had no visual or auditory impairment and no history of neurological or psychiatric disorder, or of neuro- or psychotropic drug consumption. The volunteers were first allowed to acquaint themselves with the MRI scanner environment, during a session when they tried and lay within the scanner, and were explained the objective and conditions of the experiment. The participants subsequently gave their written informed consent before taking part in the study, which was approved by the local ethical committee (CPP EST IV). One participant, unable to hear the play during the fMRI scanning, two with disturbed ECG recording and five others with fMRI acquisition disturbances (i.e., head movements) were not considered for data analysis.

\section{EXPERIMENTAL FMRI DESIGN}

For each participant, the fMRI session was carried-out while an actor gave an 11- to 14-min live performance, videotaped for subsequent analysis. The play, a monolog, was excerpted from a contemporary dramatic poem "Onysos the furious", in which old Onysos recounts his tumultuous epic (Gaudé, 2000). The noise and bore of the scanner were part of the staging, and meant to materialize a subway platform where the fiction was supposed to take place. In order to recreate a sense of dual reality and encourage the involvement of the subject in the fictional reality, the performance was made to begin as soon as (s)he entered the MRI scanner room. The actor, at the time physically present in the same room, delivered an introductory declamation as the participant was being prepared. Preparation consisted in positioning ECG electrodes, and adjusting headphones and prismatic goggles. As soon as these were on, the actor continued his performance, where he could be seen through the goggles, even as the scanner bed was made to slide into the magnet. The remainder of the play was performed in an adjacent room, owing to technical and safety considerations. From the moment the actor left the scanner environment, his performance was projected in real time to the subject who perceived the play through the goggles. The subject heard the performer's monolog through headphones, the noise of the scanner being "staged" as part of the production. The subway platform where the drama was to take place was materialized as the continuation of the scanner head coil.

\section{DEFINITION OF THEATRICAL AND SUBJECTIVE EVENTS VS BASELINE}

The stage director determined a priori within the written excerpt of the play a set of 24 textual and direction markers, committed to paper as a list of instructions to the actor and technical team (movements, positions, or tones of the actor, sound, lighting and scenery effects). These were the main staging events intended to prompt the adhesion of the spectator to the theatrical reality, and as such were assumed to have the power to induce a shift in the subject-spectator's perception of reality, from the physical reality to the fictional reality of the play. These events, referred to as theatrical events and categorized as "textual" or "direction-related", were synchronized subsequently with fMRI and ECG data acquired during the performance viewed by each subject, and reported on a timesheet per 5-s slots. With respect to the play actually performed to each participant, there were $23 \pm 1$ theatrical events, occurring in isolation or in a series, the duration of which varied within and/or between performances, spanning 1 to $4 \pm 0.55$-s slots.

A second category of event, referred to as "subjective" events, was used for analysis purposes, and determined as follows:

Immediately after the scanning session, without prior knowledge of it, the subjects were led into a different room where the video of the performance they had just been watching was replayed. The subjects were invited to describe, at their own pace, their thoughts and feelings step-by-step. When necessary and upon the subject's request, the video was paused and rewound by the interviewer. The subject's report was also transcribed onto the timesheet for every 5-s period of the videotaped play, to be synchronized with the fMRI and ECG data and the theatrical events. From the detailed accounts of their thoughts and feelings during the play it became possible to pick-up, for each spectator, the instants of adhesion to 
the theatrical reality while they had been watching the play in the scanner. Thorough reports enabled to specify for each spectator the onset and duration of thoughts and feelings related to possible shifts from one reality to the other. After having commented the whole play, the subjects answered a list of 12 questions about their involvement in the experiment, three of which being related to their adhesion to fiction, i.e., (1) Did you disregard the experimental environment? When? Specify as exactly as possible the moments. (2) Did you feel transported in another world? When? Specify as exactly as possible the moments. (3) Did you believe facing Onysos but not the actor? When? Specify as exactly as possible?

A single neutral evaluator, who had no information about the subject/spectator picked out from the comments of each subject those related to thoughts, feelings or opinions about the fiction e.g., troubled by the atrocity of episodes of Onysos' life, the violence of his vengeance, the intensity of his fury, fascinated by the magic of the dance around the fire, satisfied with Onysos' contentedness, etc. The set of events selected by the evaluator was then confronted with the participant's responses to the three above-mentioned questions. Out of the selected events those associated with moments specified by the subject in response to at least one of the three questions were validated as "subjective" events and dated according to the time code of the video. This definition allowed to estimate the extent to which the moments associated with adhesion to the fictional reality tallied with the predefined theatrical events, and allowed to specify the kind of subjective feelings associated.

Periods encompassing theatrical events with or without subjective events were considered as "active periods". The onset of an active period for fMRI analysis was systematically set to coincide with the onset of the initial theatrical event of a series of one (isolated) or several (successive) events. Within an active period, theatrical and subjective events did or did not co-occur (i.e., occur within the same 5-s slot). Only co-occurring theatrical and subjective events were considered to denote adhesion.

The time intervals without predetermined theatrical events or reported judgments or opinions about the fiction specified as subjective events, were used as the baseline condition, associated with more basic processing of visual and auditory stimulation.

\section{IMRI DATA ACQUISITION AND ANALYSIS}

Images were acquired on a 2-Tesla S200 Bruker MRI system (Bruker Medical GMBH, Ettlingen, Germany), equipped with an SK330 insert gradient coil $(30 \mathrm{mT} / \mathrm{m}, 150 \mu$ s rise time $)$ and a head volume RF coil. Functional images with blood oxygen leveldependent (BOLD) contrast were obtained using an echo planar imaging (EPI) sequence and an intercommissural AC-PC slice orientation (32 interleaved slices; matrix size $=64 \times 64$ pixels; voxel size $=4 \mathrm{~mm} \times 4 \mathrm{~mm} \times 4 \mathrm{~mm}$; TE $=43 \mathrm{~ms}$, FOV $=256 \mathrm{~mm}$, Flip angle $=90^{\circ}$ ). TR (repetition time) was set to $2.5 \mathrm{~s}$. A total of $323 \pm 17$ volumes were acquired over the duration of the performance.

The data were analyzed using Statistical Parametric Mapping 5 software (SPM5, Wellcome Department of Imaging Neuroscience, London, UK; Friston et al., 2007) implemented in Matlab V6.1 (Mathworks, Sherborn, MA, USA). The first three volumes used to reach signal equilibrium were discarded. EPI images were corrected for motion and repositioning, spatially normalized into standard co-ordinates, and smoothed spatially with an 8-mm full-width half-maximum (FWHM) Gaussian kernel. Low-frequency drifts were removed using a high-pass temporal filter (128 s).

To discern additional brain areas or those with a level of activation exceeding that associated with the basic processing of the actor's movements and speech or changes in the scenery, periods of drama-watching devoid of theatrical and/or subjective events during which the spectators were assumed to simply watch the play, were used as the baseline condition. In this way, an individual fMRI time-series was specified for each subject, to distinguish active periods with events of interest (theatrical or theatrical + subjective) from baseline periods. The hemodynamic response to active periods was modeled as a box-car function over a 20-s period subsequent to the onset of initial theatrical events. The period was set at $20 \mathrm{~s}$ (corresponding to eight fMRI volumes) in order to accommodate the longest series of theatrical and subjective events. Active periods alternated with $14 \pm 2$-s baseline periods. The BOLD signal corresponding to each active period was modeled using a canonical hemodynamic response function and its temporal derivative. This analysis was performed individually for each participant. Differences between active and baseline periods were assessed using the general linear model, yielding $t$-statistics for each voxel. The contrast images of each participant were subsequently entered without filtering in a second-level whole-brain analysis (random-effect), in order to allow generalization by accounting for inter-subject variance. All reported areas of activation were significant using a $p<0.001$ uncorrected at the voxel level and a $p<10^{-4}$ corrected at the cluster level, with a spatial extent threshold of 50 voxels. The anatomical localization of the local maxima and clusters was assessed with reference to the Montreal Neurological Institute (MNI) space.

Considering the variable, and for some participants limited, number of subjective events co-occurring with theatrical events meant to denote the subject's adhesion to fiction, subjective events were investigated using a region of interest (ROI) analysis. The ROIs were chosen according to our afore-mentioned hypotheses about the cognitive processes potentially involved in the phenomenon of adhesion to fiction while watching live theater. Consequently, six ROIs consistent with regions shown in previous neuroimaging studies to be involved in the theory of mind (Gallagher et al., 2000; Saxe and Kanwisher, 2003), empathy (Carr et al., 2003; Vollm et al., 2006), metaphor processing (Rapp et al., 2004; Eviatar and Just, 2006), and story processing (Xu et al., 2005; Yarkoni et al., 2008) were delineated within the neural network activated by the theatrical events evidenced from the whole-brain random analysis. The ROIs were defined, using the MRIcro software (Rorden and Brett, 2000), as 5-mm spheres centered on the maximum activation peak (in MNI co-ordinates) determined from the second-level analysis in the temporo-parietal junction (TPJ) and posterior superior temporal sulcus (pSTS) bilaterally, in the right middle temporal gyrus (MTG) and left ventral IFG.

We estimated the strength and direction of the relationship between the subjects' degree of adhesion to the fiction - rated as a function of the number of subjective events co-occurring with theatrical events - and the corrected BOLD signal in response to active periods contrasted against the baseline using a correlation analysis. To this purpose the mean contrast of each ROI was computed for 
each subject using the Marsbar toolbox (Brett et al., 2002) and then entered into a correlation analysis with the number of co-occurring theatrical and subjective events.

\section{ECG RECORDINGS AND DATA PROCESSING}

In order to look for possible changes in dynamic HRV associated with the occurrence of theatrical and/or subjective events, the ECG was recorded simultaneously with the fMRI images. ECG data were recorded using an MR-compatible system (EMR10: Schwarzer, Munich, Germany) equipped with a digital signal processor board receiving a separately amplified ECG channel (Physiogard, Bruker SARL, Wissembourg, France), and a trigger input from the scanner to detect MRI volumes and synchronize ECG and fMRI data. The ECG signals were sampled at $1 \mathrm{kHz}$ and transmitted via optical fibers to a standard PC. The 11 participants included in the analysis had a clean ECG recording, which was processed offline using Matlab V6.1 (Mathworks, Inc.). The pulses of the rising phase of each $\mathrm{R}$ wave were detected and computed. The R-R intervals were calculated with an accuracy of $\pm 1 \mathrm{~ms}$. Each R-R interval was plotted against the previous R-R interval to produce Poincaré plots in 30-s windows. The R-R means and inter-beat autocorrelation coefficients of ECG R-R intervals (rRR) [i.e., Pearson's correlation coefficient between $\mathrm{R}-\mathrm{R}(n)$ and $\mathrm{R}-\mathrm{R}(n+1)]$, obtained from Poincaré plots were computed over 30 -s periods synchronized with the fMRI scans $(12 \times 2.5$-s scans $)$. The Poincaré plots spread along the diagonal line. This non-linear method provides a tool to quantify the sympathetic/parasympathetic balance in the autonomic nervous system, where decrease in $\mathrm{rRR}$ denotes predominant vagal influence. To grasp changes in dynamic HRV time-locked to the occurrence of theatrical and subjective events, HRV statistics were computed for each subject over 30-s windows, made to shift by 5 -s steps (twice the fMRI repetition time), throughout the play. For each subject, the R-R means and rRR coefficients were analyzed relative to the occurrence of (1) initial theatrical events determining the onset of active periods and (2) all recorded subjective events. Prior to the onset of each initial theatrical and all subjective event, a 30-s window (considered as the HRV baseline) was defined, and made to slide by 5-s shifts to encompass the dynamic HRV at their onset.

\section{RESULTS}

\section{SUBJECTIVE EVENTS}

The thoughts and feelings reported by the participants were, above all, about the character and the intensity of his torment and distress, as opposed to the actor or the rendering of the drama. The rare instances where comments referred to the performer dealt with specific details in the actual performance, for example, a conspicuous yet totally unintentional drop of a prop by the actor, during one of the performances. This particular instance would illustrate a shift in the spectator's mind from fiction to ongoing actual events, which the subject spontaneously identified as a non-theatrical event.

The analysis of verbal reports identified a mean of $16 \pm 7$ subjective events per subject, $69 \%$ of which were found to co-occur with the predefined theatrical events. This percentage was different from chance (at $p<0.026$ ). With respect to the kind of theatrical events, $40 \%$ of subjective events matched with textual theatrical events, and $60 \%$ with direction-related markers unambiguously defined in the list of instructions provided by the stage director to the theatrical team. At the individual level, the number of co-occurring subjective and theatrical events was used as an estimate of the degree to which each spectator's subjective feelings conformed to the predefined theatrical events.

The specification of the spectators' reports showed that thoughts and feelings relating to their adhesion to the theatrical reality denoted predominantly empathy, broadly defined as the understanding of another person's feelings (Preston and de Waal, 2002), the attribution of mental states to the character (but not to the actor), and metaphor processing, as phrases or gestures were processed with reference to their significance in the represented, fictional reality.

\section{FUNCTIONAL MAGNETIC RESONANCE IMAGING}

The brain areas with significant activation associated with theatrical events, in contrast to baseline activity, are listed in Table 1.

Activation in the temporal lobe evoked by theatrical events was of greater intensity and extent in the right hemisphere, where it extended from the posterior temporal cortex to the anterior MTG (BA 21/22/40). In both hemispheres, posterior temporal activation encompassed the TPJ, and the pSTS. In the left hemisphere, the main focus of activation involved the ventral part of the IFG (BA47), the pars orbitalis, besides posterior temporal activation (BA 40/39/37).

The correlation analyses between the mean activation contrast in response to theatrical events within each $\mathrm{ROI}$ and the subjects' rate of adhesion to the fiction showed a significant positive correlation in only two ROIs in the left hemisphere (Figure 1). In the left ventral IFG $(-52,34,-10)$, the activation contrast correlated with the number of

Table 1 | Brain regions significantly activated in response to theatrical events relative to the baseline.

\begin{tabular}{|c|c|c|c|c|c|}
\hline \multirow[t]{2}{*}{$\begin{array}{l}\text { Brain regions activated } \\
\text { by theatrical events }\end{array}$} & \multirow[t]{2}{*}{$\begin{array}{l}\text { Cluster } \\
\text { size }\end{array}$} & \multirow[t]{2}{*}{$\mathbf{z}$} & \multicolumn{3}{|c|}{$\begin{array}{l}\text { Co-ordinates } \\
\text { (mm) }\end{array}$} \\
\hline & & & $\mathbf{x}$ & $\mathbf{y}$ & $\mathbf{z}$ \\
\hline R middle temporal gyrus (BA 21) & 3352 & 5.20 & 50 & -28 & -12 \\
\hline R superior temporal gyrus (BA 22) & & 5.09 & 64 & -54 & 12 \\
\hline R supramarginal gyrus (BA 40) & & 4.88 & 62 & -42 & 26 \\
\hline L inferior frontal gyrus (BA 47) & 1235 & 4.97 & -52 & 34 & -10 \\
\hline L inferior frontal gyrus (BA 47) & & 4.33 & -26 & 24 & -22 \\
\hline L inferior frontal gyrus (BA 47) & & 4.10 & -48 & 20 & 2 \\
\hline L supramarginal gyrus (BA 40) & 641 & 4.51 & -62 & -46 & 30 \\
\hline L inferior temporal gyrus (BA 37 ) & & 4.06 & -58 & -66 & 2 \\
\hline L superior temporal gyrus (BA 39) & & 4.01 & -62 & -56 & 24 \\
\hline $\mathrm{R}$ caudate tail & 219 & 3.77 & 34 & -16 & -8 \\
\hline R putamen & & 3.65 & 30 & -20 & 2 \\
\hline $\mathrm{R}$ claustrum & & 3.56 & 32 & 4 & -2 \\
\hline
\end{tabular}

Activation in the reported cerebral regions was significant at $p<0.001$ uncorrected at the voxel level. It was significant at $p<0.0001$ lexcept for the caudate cluster, $p<0.005)$ when corrected for multiple comparisons at the cluster level. L, left; $R$, right; BA, Brodmann's areas; $Z$, statistics at the voxel level; $x, y, z, M N I$ co-ordinates of the local maxima of the cluster. The anatomical labels of the activation foci were retrieved using the Automated Talairach atlas labeling system (Lancaster et al., 2000). The co-ordinates in bold figures were used as the center of the $5 \mathrm{~mm}$-spheres for the ROI analysis. 
subjective reports associated with text- and stage direction-related theatrical events $(r=0.59, p<0.05)$. In the left pSTS $(-58,-66,2)$ the mean contrast correlated significantly with the rate of subjective reports co-occurring with theatrical events based on stage directions only [i.e., striking lighting effects, etc..., $(r=0.54, p<0.05)]$.

\section{DYNAMIC HEART RATE VARIABILITY}

Figure 2 illustrates the method used to analyze the dynamic HRV response relative to the occurrence of events of interest. The analysis of variance (ANOVA), assessing the subjects' dynamic HRV response time-locked to the occurrence of initial theatrical events establishing the onset of the active periods of the individual fMRI time-series, revealed a significant decrease in $\mathrm{rRR}$ mean values at the onset of initial theatrical events $[F(1,11)=5.94, p<0.033]$. The decrease was more significant at the onset of subjective events $[F(1,11)=10.48, p<0.0079]$. With respect to $\mathrm{R}-\mathrm{R}$ mean values, only a small but significant increase at the occurrence of subjective events was found $[F(1,11)=12.14, p<0.005]$.

\section{DISCUSSION}

This study intended to capture online the neural correlates of the viewers' shift from actual to fictional reality during live drama, referred to as adhesion. Using a first-person methodology and an ecological design we aimed at identifying instants when spectators adhered to the reality represented in the play that was being acted out. Concomitant physiological recordings were intended to complement individual phenomenological accounts.

In each spectator, the instants when the fiction represented by the performance acted as reality have been identified from their individual verbal reports. A large proportion of these moments, we called "adhesion" to fiction, co-occurred with the theatrical events specified by the stage director prior to the performance. As the spectators were not aware of these theatrical events and, a fortiori, of the intentions of the stage director and/or the performer, such results would denote the key function of both phrasing and staging in inducing belief in a reality other than that inherent in the actual perceptual inputs. These instants were found to be associated with a significant transient

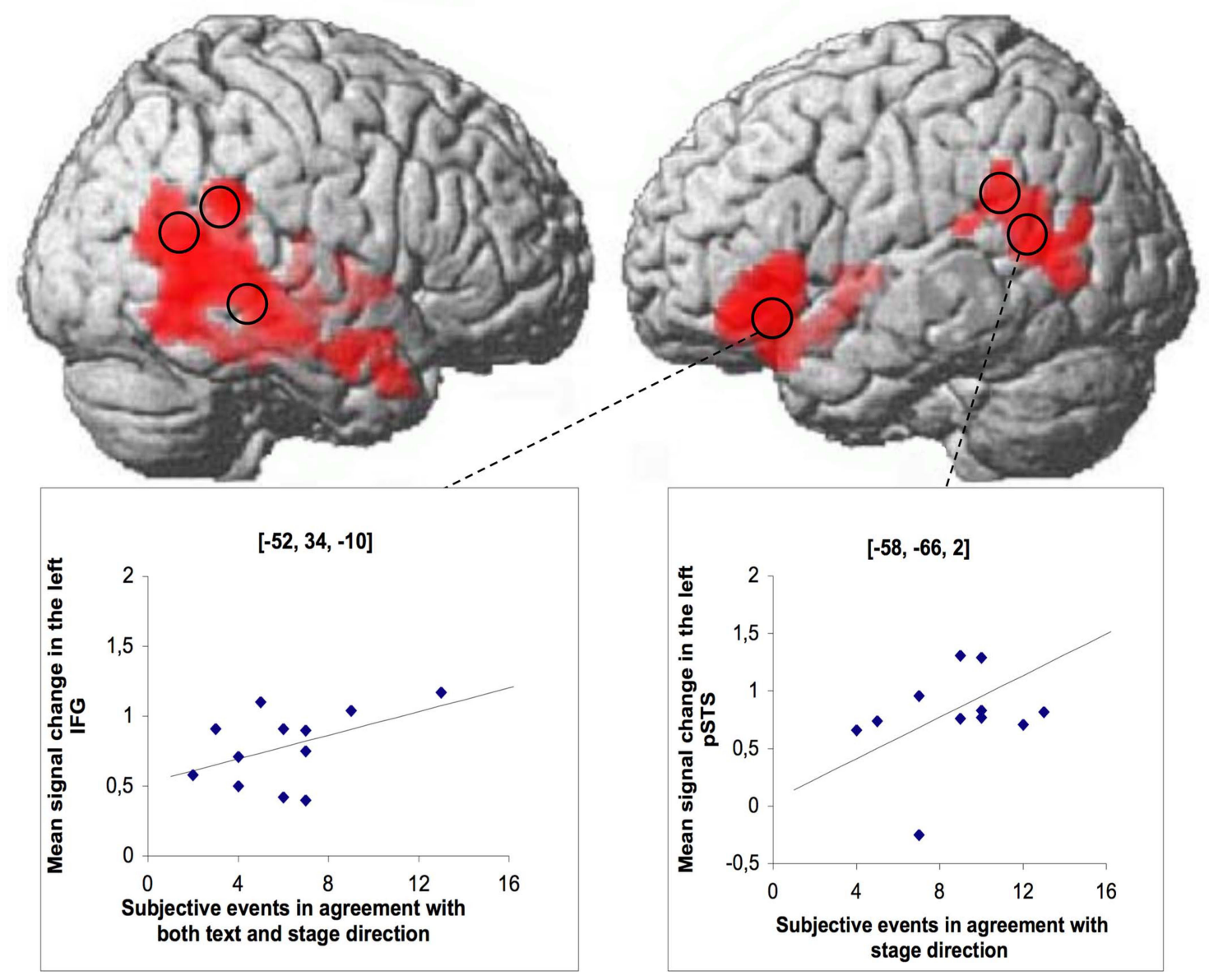

FIGURE 1 | Brain areas (in red) with significant BOLD signal differences when contrasting periods of the play with and without theatrical events. The activated clusters are significant at $p<0.0001$, corrected (cf. Table 1). Correlation analyses between the subjective events in agreement with theatrical events (assumed to reflect adhesion to the theatrical reality) and the mean signal changes (in arbitrary units) were computed for each subject in the six

regions of interest circumscribed by black circles. Encapsulated figures: A significant positive correlation between activation in response to theatrical events and the adhesion rate was only found in the left anterior IFG for subjective responses related to both text- and direction-related markers, and in the left pSTS for subjective responses related to direction markers. The co-ordinates in brackets are those of the ROI center. 


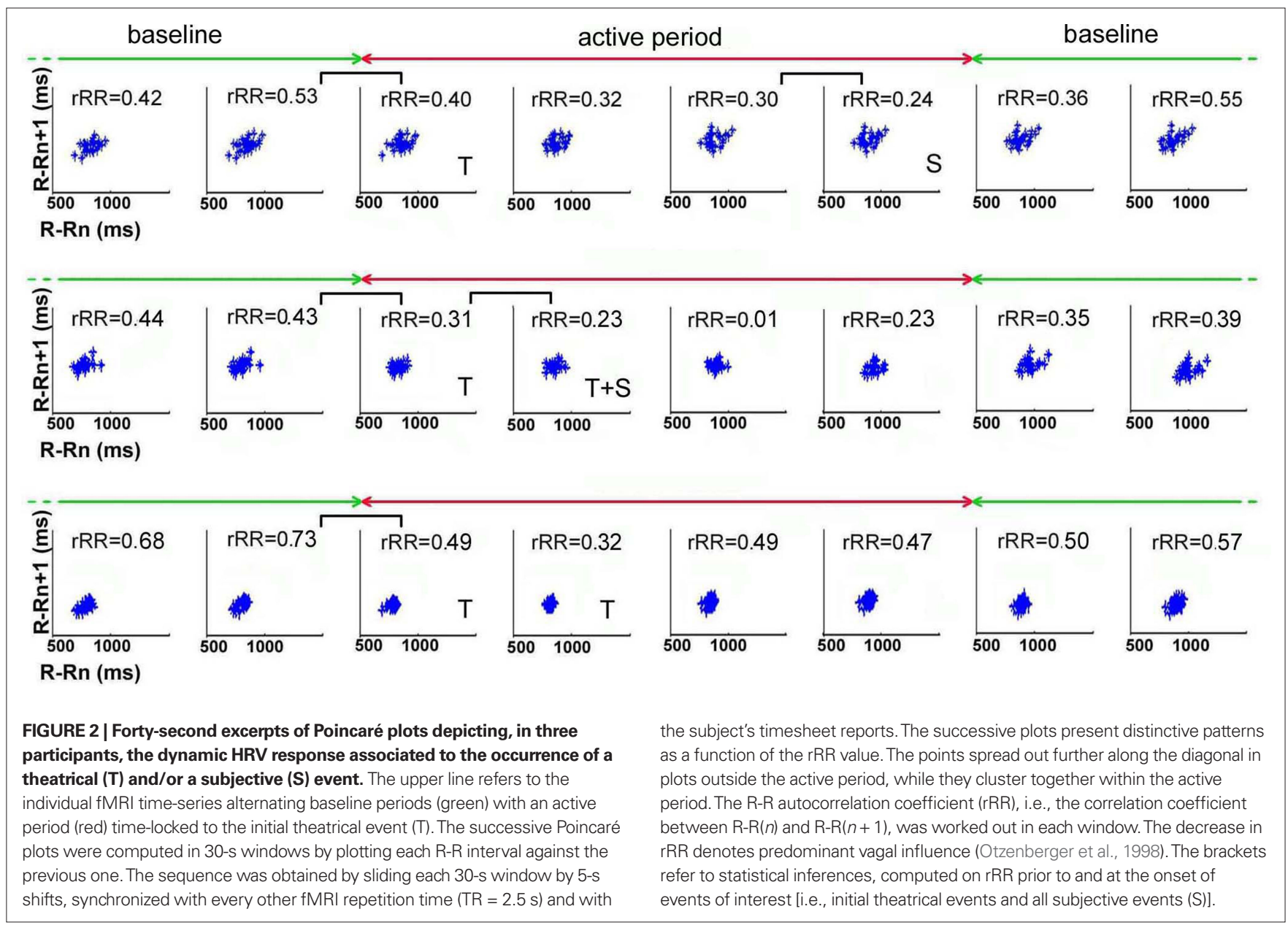

decrease in dynamic HRV. In the brain activation pattern elicited by the predefined theatrical events designed by the stage director to prompt the adhesion of the spectators, the signal changes in two regions, in the left ventral IFG (BA 47) and pSTS positively correlated with the degree of adhesion of the spectators, induced by these events. More specifically, activation in the left IFG correlated significantly with the degree of adhesion prompted by theatrical events based on both text and staging, whereas in the left pSTS, it correlated with the theatrical events based on stage direction only.

\section{ADHESION TO FICTION DEPENDS ON BOTH VERBAL AND SOCIAL PROCESSING}

The left ventral IFG and left pSTS, known to be part of the language network, have been shown to be involved in context-relevant verbal processing, namely in text comprehension (Xu et al., 2005). In a recent meta-analysis of neuroimaging studies on text comprehension, these two regions have been found to form a sub-network within the "extended language network" (Ferstl et al., 2008). Their involvement in the process of adhesion to live dramatic fiction might suggest that entering the reality represented in a play, essentially relies, at least in part, on verbal processing. However, these two areas have more recently been shown to be involved in social cognition, i.e., understanding others and one's self, and processes at the interface between the self and others.
In the left ventral IFG, the peak voxel $(-52,34,-10)$ of the ROI the activation of which correlated with the amount of subjective events matching with both text- and direction-related theatrical events, closely fitted the co-ordinates $(-50,37,-12)$ of the anterior part of the left ventral IFG, known to play a key role in the process of understanding metaphors (Rapp et al., 2004). Activation in the ventral IFG (BA 45/47) has also been reported in evaluative judgment in social and esthetic domains (Zysset et al., 2002; Cunningham et al., 2003; Jacobsen et al., 2006). In good-bad evaluative judgments, Cunningham et al. (2003) observed increased ventrolateral prefrontal activity in judgments marked by greater ambivalence. As for social appraisal, esthetic judgments also specifically activate the ventrolateral prefrontal cortex (BA 45/47), part of a set of areas comprising the anterior frontomedian cortex and the precuneus (Jacobsen et al., 2006). Increased activation in BA $45 / 47$ as a function of stimulus complexity specific to esthetic judgment observed in the Jacobsen's study suggests that this area plays a specific role in evaluative assessments according to the person's value system. In the present study, the positive correlation between activation in BA45/47 and the number of subjective events co-occurring with theatrical events related to both textual and direction markers might suggest some kind of esthetic judgment about both the writing and the artistic conception of the play. With reference to the philosophical debate about the "suspension of disbelief", the 
involvement of the left ventral IFG could be viewed as underlying a mental process based on the knowledge that what is going on is an artifact intended to mean something else with subsequent metaphor processing gating the spectator's adhesion to fiction. Alternatively the involvement of this cortical area could be related to the esthetic appreciation of the way the performance achieves the fiction, or to the evaluative judgment of the plot or character.

As regards the left pSTS, besides its critical role in the integration of different types of sensory information within and across modalities into a coherent percept (Beauchamp et al., 2004), its involvement in the passive viewing of eye, lip, face, hand, and body motion (Puce et al., 1998) has been shown to be sensitive to the context within which the biological motion is perceived. Several recent functional neuroimaging studies have provided clues hinting at its involvement in the interpretation of other people's actions in relation to their intentions (Pelphrey et al., 2004; Vander Wyk et al., 2009). Its central role in social cognition was suggested by its involvement as a part of a distributed network selectively recruited when reasoning about the content of mental states of others (Martin and Weisberg, 2003; Saxe et al., 2004; Saxe, 2006). Indeed, tasks designed to investigate the theory of mind, based on false belief reasoning, have revealed a very consistent pattern of brain activation, including the $\mathrm{MPFC}$, medial precuneus, and the TPJ, bilaterally. However, Saxe et al. (2006) observed a differential involvement of the medial and lateral parts of this network, depending on the task, showing that the two medial regions were recruited when the task implied judgments about other people, and that the temporo-parietal regions were recruited only when subjects thought about others' thoughts. In the present experience, the positive correlation between activation in the pSTS and subjective events co-occurring only with direction-related theatrical events could be in agreement with the involvement of this region in the interpretation of intended action. However, in the context of adhesion, the interpretation of action does not bear on the intention of the performer pretending to be and act as someone else, but on the intention of the characters within the fictional reality, which requires a shift in perspective.

\section{LIVE THEATER TELLS A STORY BUT IN THE FORM OF ACTION}

The left ventral IFG and left pSTS, activated in relation to the subjects' adhesion to fiction, were only part of the larger pattern of brain activation induced by the occurrence of theatrical events, which altogether included the left ventral part of the IFG (BA47), the pars orbitalis, and the posterior temporal area encompassing bilaterally the TPJ and the pSTS, although predominant in the right hemisphere where it extended to the anterior MTG (BA 21/22/40). All these regions are consistently engaged in text comprehension, together with the cortical midline structures [dorsomedial prefrontal cortex (dmPFC) and PCC]. As a form of storytelling based on the imitation of actions, in contrast to a spoken or written story, a dramatic performance does not call for coherence building or require the construction of dynamic representations of the situations reported, which have been shown to rely on the dmPFC (Xu et al., 2005; Yarkoni et al., 2008).

In addition to their involvement in narrative processing, these midline cortical structures, which are part of a consistent network of brain activity "at rest", are also engaged in self-referential processing across a variety of functional domains (Gusnard and Raichle, 2001; Northoff and Bermpohl, 2004; Northoff et al., 2006). A recent meta-analysis demonstrated that these structures overlapped with brain regions typically involved in cognitive social processes, namely involving self-other distinction and exchange (Schilbach et al., 2008). In narrative processing, the involvement of the dmPFC has been related to the decoding of the beliefs, feelings or intentions of agents (Vogeley et al., 2001) and the PCC to the linking of textual information with a subject's knowledge about the real world; both processes are central to the construction of mental representations (Gallagher et al., 2000; Ferstl et al., 2005; Xu et al., 2005; Wilson et al., 2008). Cavanna and Trimble (2006) suggested that these structures, also active during conscious resting state, were engaged in continuous information gathering and representation of the self and of the external world. Since the story is recounted in the form of action and therefore does not require the viewers to represent the situation, one may wonder whether representations of the self and the world are necessarily called for. In addition, the PCC have been shown to be involved with the medial prefrontal and lateral temporo-parietal cortices in assigning first-person perspective (Vogeley and Fink, 2003).

In the particular context of a live story being acted out, the absence of significant involvement of the midline structures may thus be interpreted in different ways. This may result from the fact that a story enacted may not, at least not to the same degree as processing a spoken or written story would, require the linking of incoming information with prior knowledge or experience to achieve coherence building (Ferstl and von Cramon, 2001) or to evaluate facts on the basis of personal experience (Zysset et al., 2002). The absence of significant activation in these areas may also be considered in reference to their usual involvement in social cognition relying on self-referential information to interpret external inputs, and in particular, others (Buckner and Carroll, 2007; Schilbach et al., 2008).

As during a performance, the spectators are enjoined to accept the represented situation as true, or in other words, to take the fictional world for granted in spite of the actual reality grasped through sensory information, it implies that the spectators, in a way, disengage or disconnect themselves from the immediate significance of sensory information in order to process the constituent actions and events of a fiction. That being the case, one may wonder whether this could not be conditioned by the absence of activation in the midline cortical areas.

\section{IS ADHESION TO DRAMATIC FICTION CONSTRAINED BY SUSPENDED SELF-REFERENTIAL EMOTIONAL PROCESSING?}

The theatrical events designed to prompt the adhesion of the spectator were associated with a significant decrease in dynamic HRV, which was significantly more pronounced for subjective events. The ECG was recorded because we had expected to find instead an increase in dynamic HRV as a result of changes in emotional state putatively associated to the adhesion to a dramatic fiction. Indeed, emotional states typically increase the sympathetic activity, which in turn increases the dynamic HRV (McCraty et al., 1995). Consequently various psychological interventions, namely operant conditioning of heart rate (Hatch et al., 1990) and neutral hypnosis (DeBenedittis et al., 1994) have been proposed to decrease the 
dynamic HRV. A decrease in dynamic HRV similar to that reported for hypnotic states have been observed in meditation-based selfregulatory management of emotion (Takahashi et al., 2005). From these data, one may wonder whether the dynamic HRV which, in spectators of live drama, decreases as their involvement in the fiction increases might not argue for a kind of emotional regulation. Thence one may speculate about a possible link between this unexpected but robust change in dynamic HRV and the absence of significant activation in the CMS, particularly in the precuneus, implicated both in the attribution of emotions to the self and to other people (Ochsner et al., 2004), and in the assignment of the view point of the observing self (Vogeley and Fink, 2003).

\section{IS ADHESION TO FICTION IN LIVE THEATER LINKED TO A PARTICULAR STATE OF AWARENESS?}

Should there be a connection between alterations in the dynamic HRV and the absence of significant activation in the precuneus when processing a story told in the form of actions, then one might speculate about a particular state of awareness induced by "being in the theater" and accepting to deal with fiction as if it were reality.

Now, decrease in dynamic HRV, which denotes predominant vagal influence in the sympathetic/parasympathetic balance of the autonomic nervous system is considered as a quantitative measure of hypnotic depth (Diamond et al., 2008). In parallel, neuroimaging studies of altered states of consciousness such as the vegetative state (Laureys et al., 2004), anesthesia (Fiset et al., 1999), sleep (Maquet, 1997), and the hypnotic state (Faymonville et al., 2006) provided evidence of the involvement of the precuneus and the adjacent PCC in the neural network subserving self-awareness and conscious experience. Accordingly, suspension of activity in the

\section{REFERENCES}

Abraham, A., von Cramon, D. Y., and Schubotz, R.I. (2008). Meeting George Bush versus Meeting Cinderella: the neural response when telling apart what is real from what is fictional in the context of our reality. J. Cogn. Neurosci. 20, 965-976.

Aristotle. (350 B.C.E). Poetics, Vol. Book VI, ed. T. b. S. H. Butcher (http://classics.mit.edu).

Artaud,A. (1938). Le théâtre et son double. Paris: Gallimard, p. 189.

Bartels, A., and Zeki, S. (2004). Functional brain mapping during free viewing of natural scenes. Hum. Brain Mapp. 21, 75-85.

Batson, C. D., Early, S., and Salvarani, G. (1997). Perspective taking: imagining how another feels versus imaging how you would feel. Pers. Soc. Psychol. Bull. 23, 751-758.

Beauchamp, M. S., Lee, K. E., Argall, B. D., and Martin, A. (2004). Integration of auditory and visual information about objects in superior temporal sulcus. Neuron 41, 809-823.

Brett, M., Anton, J. L., Valabregue, R., and Poline, J. B. (2002). "Region of interest analysis using an SPM toolbox," precuneus was considered as a central metabolic feature of the hypnotic state, characterized by temporary loss of body and self representation (Faymonville et al., 2006). As regards the present study, it may be conjectured that the significant decrease in dynamic HRV associated with the absence of significant activation in the precuneus would substantiate the hypothesis of a change in the state of consciousness of live drama viewers enabling them to adhere to the fiction.

This parallel lead us to hypothesize that, like hypnosis, viewing live drama induces a subtle alteration of consciousness allowing to dissociate components of behavior. The hypnotic state typically results from an induction procedure based on suggestions of relaxation or imaginative or ideational experience, during which critical judgment is suspended. As an outcome of the full involvement in such experience, the subject may experience changes in the perception of peripheral inputs, such as pain reduction. In live theater, the induction procedure that urges the spectators to divert their mind from incoming factual information and enter the dramatic fiction could be either the theatrical events, the plot or "arrangement of incidents" in Aristotle's words (Aristotle, 350 B.C.E), or the "willing suspension of disbelief" proposed by Coleridge. The ensuing suspension of self-reference and emotional processing could be one expression of the cathartic function of drama put forward by Aristotle, which is consubstantial with esthetic pleasure. "Catharsis can only happen to someone who in the presence of a work of art accepts the role of an esthetic spectator" (Schaper, 1968).

\section{ACKNOWLEDGMENT}

This study was supported by funds from the Direction for Research and Higher Education of Region Alsace (Grant 06/901/346). of sympatho-vagal balance. Int. J. Clin. Exp. Hypn. 42, 140-152.

Diamond, S. G., Davis, O. C., and Howe, R. D. (2008). Heart-rate variability as a quantitative measure of hypnotic depth. Int. J. Clin. Exp. Hypn. 56, 1-18.

Eviatar, Z., and Just, M. A. (2006). Brain correlates of discourse processing: an fMRI investigation of irony and conventional metaphor comprehension. Neuropsychologia 44, 2348-2359.

Faymonville, M.-E., Boly, M., and Laureys, S. (2006). Functional neuroanatomy of the hypnotic state. J. Physiol. (Paris) 99, 463-469.

Ferstl, E. C., Neumann, J., Bogler, C., and von Cramon, D. Y. (2008). The extended language network: a metaanalysis of neuroimaging studies on text comprehension. Hum. Brain Mapp. 29, 581-593.

Ferstl, E. C., Rinck, M., and von Cramon, D. Y. (2005). Emotional and temporal aspects of situation model processing during text comprehension: an eventrelated fMRI study. J. Cogn. Neurosci. 17, 724-739.

Ferstl,E. C., and von Cramon, D. Y. (2001). The role of coherence and cohesion in text comprehension: an eventrelated fMRI study. Cogn. Brain Res. $11,325-340$.

Fiset, P., Paus, T., Daloze, T., Plourde, G., Meuret, P., Bonhomme, V., Hajj-Ali, N., Backman, S. B., and Evans, A. C. (1999). Brain mechanisms of propofol-induced loss of consciousness in humans: a positron emission tomographic study. J. Neurosci. 19, 5506-5513.

Friston, K. J., Ashburner, J., Kiebel, S., Nichols, T. E., and Penny, W.D. (2007). Statistical Parametric Mapping: The Analysis of Functional Brain. London: Academic Press.

Gallagher, H. L., Happe, F., Brunswick, N., Fletcher, P.C., Frith, U., and Frith, C. D (2000). Reading the mind in cartoons and stories: an fMRI study of 'theory of mind' in verbal and nonverbal tasks. Neuropsychologia 38, 11-21.

Gaudé, L. (2000). Onysos le furieux. Arles: Editions Actes-Sud.

Godard, J.-L. (1999). JLG/JLG. Paris: P.O.L.

Gusnard, D. A., and Raichle, M. E. (2001). Searching for a baseline: functional imaging and the resting human brain. Nat. Rev. Neurosci. 2, 685-694. 
Hatch, J. P., Borcherding, S., and Norris, L. K. (1990). Cardiopulmonary adjustments during operant heart rate control. Psychophysiology 27, 641-648.

Jacobsen, T., Schubotz, R. I., Höfel, L., and von Cramon, D. Y. (2006). Brain correlates of aesthetic judgment of beauty. Neuroimage 29, 276-285.

Lancaster, J. L., Woldorff, M. G., Parsons, L. M., Liotti, M., Freitas, C. S., Rainey, L., Kochunov, P. V., Nickerson, D., Mikiten, S. A., and Fox, P. T. (2000). Automated Talairach atlas labels for functional brain mapping. Hum. Brain Mapp. 10, 120-131.

Laureys, S., Owen, A. M., and Schiff, N. D. (2004). Brain function in coma, vegetative state, and related disorders. Lancet Neurol. 3, 537-546.

Lutz, A., Lachaux, J.-P., Martinerie, J., and Varela, F. J. (2002). Guiding the study of brain dynamics by using firstperson data: synchrony patterns correlate with ongoing conscious states during a simple visual task. Proc. Natl. Acad. Sci. U.S.A. 99, 1586-1591.

Maquet, P. (1997). Positron emission tomography studies of sleep and sleep disorders. J. Neurol. 244, S23-S28.

Martin, A., and Weisberg, J. (2003). Neural foundations for understanding social and mechanical concepts. Cogn. Neuropsychol. 20, 575-587.

McCraty, R., Atkinson, M., Tiller, W. A., Rein, G., and Watkins, A. D. (1995). The effects of emotions on shortterm power spectrum analysis of heart rate variability. Am. J. Cardiol. 76, 1089-1093.

Northoff, G., and Bermpohl, F. (2004). Cortical midline structures and the self. Trends Cogn. Sci. 8, 102-107.

Northoff, G., and Heinzel, A. (2006). First-person neuroscience: a new methodological approach for linking mental and neuronal states. Philos. Ethics Humanit. Med. 1, E3.

Northoff, G., Heinzel, A., de Greck, M., Bermpohl, F., Dobrowolny, H., and Panksepp, J. (2006). Self-referential processing in our brain - a metaanalysis of imaging studies on the self. Neuroimage 31, 440-457.

Ochsner, K. N., Knierim, K., Ludlow, D. H., Hanelin, J., Ramachandran, T., Glover, G., and Mackey, S. C. (2004). Reflecting upon feelings: an fMRI study of neural systems supporting the attribution of emotion to self and other. J. Cogn. Neurosci. 16, 1746-1772.
Oldfield, R.C. (1971). The assessment and analysis of handedness: the Edinburgh inventory. Neuropsychologia 9, 97-113.

Otzenberger, H., Gronfier, C., Simon, C., Charloux, A., Ehrhart, J., Piquard, F., and Brandenberger, G. (1998). Dynamic heart rate variability: a tool for exploring sympathovagal balance continuously during sleep in men. Am. J. Physiol. Heart Circ. Physiol. 275, 946-950.

Pelphrey, K. A., Morris, J.P., and McCarthy, G. (2004). Grasping the intentions of others: the perceived intentionality of an action influences activity in the superior temporal sulcus during social perception. J. Cogn. Neurosci. 16, 1706-1716.

Preston, S. D., and de Waal, F. B. (2002). Empathy: its ultimate and proximate bases. Behav. Brain Sci. 25, 1-20; discussion 20-71.

Puce, A., Allison, T., Bentin, S., Gore, J. C., and McCarthy, G. (1998). Temporal cortex activation in humans viewing eye and mouth movements. J. Neurosci. 18, 2188-2199.

Rapp, A. M., Leube, D. T., Erb, M., Grodd, W., and Kircher, T. T. J. (2004). Neural correlates of metaphor processing. Cogn. Brain Res. $20,395-402$.

Rorden, C., and Brett, M. (2000). Stereotaxic display of brain lesions. Behav. Neurol. 12, 191-200.

Rosebury, B. J. (1979). Fiction emotion and 'belief': a reply to Eva Schaper. $B r$. J. Aesthetics 19, 120-130.

Saxe, R. (2006). Uniquely human social cognition. Curr. Opin. Neurobiol. 16, 235-239.

Saxe, R., Carey, S., and Kanwisher, N. (2004). Understanding other minds: linking developmental psychology and functional neuroimaging. Annu. Rev. Psychol. 55, 87-124.

Saxe, R., and Kanwisher, N. (2003). People thinking about thinking people: the role of the temporo-parietal junction in "theory of mind". Neuroimage 19, 1835-1842.

Saxe, R., Moran, J. M., Scholz, J., and Gabrieli, J. (2006). Overlapping and non-overlapping brain regions for theory of mind and self reflection in individual subjects. Soc. Cogn. Affect. Neurosci. 1, 229-234.

Schaper, E. (1968). Aristotle's catharsis and aesthetic pleasure. Philos. Q. 18, 131-143.
Schaper, E. (1978). Fiction and the suspension of disbelief. Br. J. Aesthetics $18,31-44$.

Schilbach, L., Eickhoff, S. B., RotarskaJagiela, A., Fink, G. R., and Vogeley, K. (2008). Minds at rest? Social cognition as the default mode of cognizing and its putative relationship to the "default system" of the brain. Conscious. Cogn. $17,457-467$.

Simons, J. S., Henson, R. N. A., Gilbert, S. J., and Fletcher, P.C. (2008). Separable forms of reality monitoring supported by the anterior prefrontal cortex. $J$. Cogn. Neurosci. 20, 447-457.

Spiers, H. J., and Maguire, E. A. (2006). Spontaneous mentalizing during an interactive real world task: an fMRI study. Neuropsychologia 44, 1674-1682.

Takahashi, T., Murata, T., Hamada, T., Omori, M., Kosaka, H., Kikuchi, M., Yoshida, H., and Wada, Y. (2005). Changes in EEG and autonomic nervous activity during meditation and their association with personality traits. Int. J. Psychophysiol. 55, 199-207.

Turner, M. S., Simons, J. S., Gilbert, S. J., Frith, C. D., and Burgess, P. W. (2008). Distinct roles for lateral and medial rostral prefrontal cortex in source monitoring of perceived and imagined events. Neuropsychologia 46, 1442-1453.

Vander Wyk, B., C., Hudac, C., M., Carter, E., J., Sobel, D., M., and Pelphrey, K. A. (2009). Action understanding in the superior temporal sulcus region. Psychol. Sci. 20, 771-777.

Varela, F.J. (1996). Neurophenomenology: a methodological remedy for the hard problem. J. Conscious. Stud. 3 , 330-349.

Varela, F. J., and Shear, J. (1999). Firstperson methodologies: what, why, how? J. Conscious. Stud. 6, 1-14.

Vogeley, K., Bussfeld, P., Newen, A., Herrmann, S., HappÈ, F., Falkai, P., Maier, W., Shah, N. J., Fink, G. R., and Zilles, K. (2001). Mind reading: neural mechanisms of theory of mind and self-perspective. Neuroimage 14, 170-181.

Vogeley, K., and Fink, G. R. (2003). Neural correlates of the first-person-perspective. Trends Cogn. Sci. 7, 38-42.

Vollm, B. A., Taylor, A. N. W., Richardson, P., Corcoran, R., Stirling, J., McKie, S., Deakin, J. F. W., and Elliott, R. (2006) Neuronal correlates of theory of mind and empathy: a functional magnetic resonance imaging study in a nonverbal task. Neuroimage 29, 90-98.

Wilms, M., Schilbach, L., Pfeiffer, U., Bente, G., Fink, G. R., and Vogeley, K. (2010). It's in your eyes - using gaze-contingent stimuli to create truly interactive paradigms for social cognitive and affective neuroscience. Soc. Cogn. Affect. Neurosci. 5, 98-107.

Wilson, S. M., Molnar-Szakacs, I., and Iacoboni, M. (2008). Beyond superior temporal cortex: intersubject correlations in narrative speech comprehension. Cereb. Cortex 18, 230-242.

Xu, J., Kemeny, S., Park, G., Frattali, C., and Braun, A. (2005). Language in context: emergent features of word, sentence, and narrative comprehension. Neuroimage 25, 1002-1015.

Yarkoni, T., Speer, N. K., and Zacks, J. M. (2008). Neural substrates of narrative comprehension and memory. Neuroimage 41, 1408-1425.

Zacks, J. M., Braver, T. S., Sheridan, M. A., Donaldson, D. I., Snyder, A. Z., Ollinger, J. M., Buckner, R. L., and Raichle, M. E. (2001). Human brain activity time-locked to perceptual event boundaries. Nat. Neurosci. 4, 651-655.

Zysset, S., Huber, O., Ferstl, E., and von Cramon, D. Y. (2002). The anterior frontomedian cortex and evaluative judgment: an fMRI study. Neuroimage 15, 983-991.

Conflict of Interest Statement: The authors declare that the research was conducted in the absence of any commercial or financial relationships that could be construed as a potential conflict of interest.

Received: 26 March 2010; paper pending published: 04 May 2010; accepted: 10 July 2010; published online: 19 August 2010.

Citation: Metz-Lutz M-N, Bressan Y, Heider N and Otzenberger H (2010) What physiological changes and cerebral traces tell us about adhesion to fiction during theaterwatching? Front. Hum. Neurosci. 4:59. doi: 10.3389/fnhum.2010.00059

Copyright () 2010 Metz-Lutz, Bressan, Heider and Otzenberger. This is an openaccess article subject to an exclusive license agreement between the authors and the Frontiers Research Foundation, which permits unrestricted use, distribution, and reproduction in any medium, provided the original authors and source are credited. 